\title{
Deficit Attention Disorder: Partisanship, Issue Importance and Concern About Government Overspending
}

\author{
John V. Kane ${ }^{1}$ (D) $\cdot$ Ian G. Anson ${ }^{2}$
}

Accepted: 15 February 2022

(C) The Author(s), under exclusive licence to Springer Science+Business Media, LLC, part of Springer Nature 2022

\begin{abstract}
Political action and electoral behavior often stem from a conviction that an issue is important. Yet despite a growing literature on partisan bias, it remains unclear whether partisan attachment also affects the perceived importance of various issues. We propose a theory of partisan-motivated issue attention (PMIA), wherein citizens satisfy partisan instincts by shifting the perceived importance of an issue. We apply our theory to an issue involving a fundamental tool of the federal governmentthe power to deficit-spend-and test the hypothesis that partisans' concern about government overspending significantly changes depending on which party presides over deficit-spending. Leveraging pre-registered experimental and observational studies, we find strong support for this hypothesis among both Republicans and Democrats. Lastly, using text analytical methods, we also find evidence of PMIA in televised partisan media. Our study thus demonstrates that putative concern about deficit-spending contains a sizable partisan component and, more broadly, uncovers an additional means by which partisan bias guides citizens' attitude formation on policy-relevant issues in the United States.
\end{abstract}

Keywords Partisanship $\cdot$ Motivated reasoning $\cdot$ Deficits $\cdot$ Debt $\cdot$ Presidency

Replication files are located on the Political Behavior Dataverse: https://doi.org/10.7910/DVN/ ZWLFWO.

John V. Kane

john.kane@nyu.edu

Ian G. Anson

iganson@umbc.edu

1 New York University, New York, NY, USA

2 University of Maryland, Baltimore County, Baltimore, MD, USA 
“George [W.] Bush's policies have taken us from a projected \$5.6 trillion surplus at the end of the Clinton administration to massive deficits and nearly $\$ 4$ trillion in new debt today."

-- Democratic Presidential Candidate Barack Obama (2008)

"We're a debtor nation... We've got to get rid of the $\$ 19$ trillion in debt."

--Republican Presidential Candidate Donald Trump (2016) ${ }^{1}$

Political action and electoral behavior are ultimately rooted in a conviction that an issue, or set of issues, is important. Existing literature demonstrates that perceived issue importance drives a variety of consequential outcomes, including evaluations of political elites and vote choice, and that passion for particular issues undergirds so-called "issue publics" that exert substantial influence upon the policymaking process (e.g., Krosnick, 1990).

At the same time, contemporary political behavior research places a strong emphasis on the biasing effects of partisan identification on issue perceptions. Specifically, a wealth of scholarship demonstrates that partisans reason about political issues in a "directional" fashion, reinforcing attitudes that are congenial to their preferred political party and/or antagonistic toward their non-preferred party (Bullock \& Lenz, 2019; Flynn et al., 2017; Lodge \& Taber, 2013). On matters involving public policies, this literature has often focused on the influence of partisan attachments on issue stances (Cohen, 2003), biases in factual perceptions of those issues (e.g., Achen \& Bartels, 2016), or the attribution of responsibility for outcomes related to those issues (Rudolph, 2006).

Less understood, however, is the extent to which partisanship might also influence the degree to which citizens are concerned about, or attend to, a political issue. In this article, we propose a theory of partisan-motivated issue attention (PMIA). Our central argument is that, even when partisans are relatively accurate in their perceptions of a particular issue, and also "correctly" assign responsibility for that issue to a culpable elite, the systematic shifting of an issue's importance represents an additional avenue by which citizens can satisfy the desire for a partisan-congenial worldview (Bisgaard \& Slothuus, 2018).

To investigate the empirical merits of PMIA, we focus on the case of U.S. federal deficit spending (i.e., government overspending), an issue that fundamentally determines what the federal government can accomplish. ${ }^{2}$ In this policy domain, extant research has largely focused on how so-called partisan "perceptual screens" shape attitudes about the size of budget deficits (e.g., Achen and Bartels; Bullock et al., 2015; Meirick, 2016). Beyond uncovering these biases in partisans' factual knowledge about an issue, additional research suggests that partisans differ in their attributions of blame for government overspending (e.g., Rudolph, 2003, 2006). In other

\footnotetext{
1 See The New York Times (2008) and Kessler (2016), respectively.

2 We use the term "overspending" simply to mean (government) expenditures exceeding revenue, without any insinuation that outlays are too high and/or tax revenue is too low.
} 
words, partisan biases lead citizens to adjust their beliefs about the magnitude of, and responsibility for, government overspending.

But by neglecting the potential for motivated issue attention, extant literature on the politics of government overspending remains underdeveloped. Given the "facts" of budget deficits (e.g., their existence, size, and/or growth over time, etc.), as well as the president's perceived accountability for deficit spending (Morgan, 2009), we hypothesize that partisan attachments will alter citizens' perceived importance of government overspending. Specifically, our theory of PMIA predicts that partisans will exhibit less concern for deficits, and thus be less inclined to prioritize deficit reduction, when an inparty (versus outparty) president occupies the White House. Given that government debt has come to represent an increasingly large share of U.S. Gross Domestic Product (see Fig. 7 in the Appendix), this hypothesis stands in notable contrast to a more naïve, yet theoretically plausible, expectation wherein rising deficit spending (and, thus, additional debt accumulation) leads all citizens to view overspending — and policies aimed at deficit reduction — as being increasingly important. $^{3}$

To test this hypothesis, we pursue three complementary sets of analyses leveraging experimental, cross-sectional, and panel data, as well as textual data obtained from televised partisan media transcripts. In each of these analyses, we find strong evidence of PMIA, with partisans exhibiting less concern about deficits when an inparty president holds office, and vice versa.

Beyond detecting biased attention on the specific issue of government overspending, our study offers several additional insights: (1) biased issue attention can occur in the mass public even in the absence of explicit cues from partisan elites; (2) the inclination to behave in this biased fashion is stronger for those with stronger party attachment; and, (3) two distinct mechanisms-attenuation and augmentation of perceived importance-operate in tandem to produce these effects. In addition, though fiscal responsibility and limited government are a purported pillar of conservatism (e.g., Feldman \& Zaller, 1992), we find that Republicans do not substantially differ from Democrats with respect to exhibiting partisan bias on the issue of government overspending.

In all, the present study expands our collective understanding of the avenues by which partisan biases manifest themselves in American politics. Our study also contributes to the growing literature on the relationship between partisanship and policy attitudes (Barber \& Pope, 2019; Mason, 2015), with potentially important implications for democratic accountability. Finally, our study offers novel insights into how government deficits can function as a perennial source of political ammunition for parties out of power.

\footnotetext{
3 For example, public concern about unemployment increased sharply following the 2008 financial crisis (Steinhauser 2009), and concern about climate change has steadily increased alongside global warming itself (Kennedy 2020).
} 


\section{Issue Importance}

Perceived issue importance (i.e., the degree to which citizens attend to, or feel passionate about, particular issues) plays a crucial role in American democracy (Krosnick, 1990). It increases the salience of, and weight assigned to, government performance on issues (Fournier et al., 2003), and alters the types of information to which citizens attend and selectively expose themselves (Bolsen \& Leeper, 2013). Belief about the importance of an issue is also predictive of the strength of attitudes about that issue and, thus, prospects for opinion change, with high-importance issues being more resilient to alternative framing than low-importance issues (Lecheler et al., 2009).

Citizens' perception that an issue is important also allows for the formation of "issue publics"-i.e., groups of citizens interested in, and often highly politically active on, a particular issue domain (e.g., Hill, 2021). Such groups stand to exert substantial political influence. In a similar vein, prior research suggests that public concern about budgetary matters is capable of influencing the legislative agenda of Congress (Jones \& Baumgartner, 2004) as well as the agenda of the president (Canes-Wrone \& Shotts, 2004).

\section{Issue Importance: The Case of U.S. Government Overspending}

Since the 1970 s, the federal government has run a deficit nearly every year. ${ }^{4}$ Consequently, deficit spending been a persistent issue in contemporary American political discourse. Debates over major legislative initiatives (e.g., a "Green New Deal", "Medicare for All", and the "Tax Cuts and Jobs Act" of 2017) routinely invoke budgetary costs and projected impact on deficits (Levitan, 2019; Liu \& Eibner, 2019), while debates over "raising the debt ceiling" have become a recurring feature of American politics (Dennis, 2019; Mann \& Ornstein, 2013). Further, deficits and debt impose constraints upon presidential agendas (Crosby \& Holbrook, 2019; Morgan, 2009), and presidents of both parties face pressures to discuss the deficit and national debt in public statements (Fisher, 2012; Wood, 2004). In Congress, requiring a "balanced budget" has been the most frequently proposed amendment to the U.S. Constitution since 1999 (Desilver, 2018). And, among members of the public, "the budget deficit" has long ranked among the public's top policy priorities (Meirick, 2016; Pew Research Center, 2019; see also Gruszczynski, 2019). For example, in a study of public support for a balanced budget amendment between 1978 and 2014, authors Crosby and Holbrook (2019) find that support has ranged from 60 to nearly $90 \%$.

Perhaps because the federal budget is essentially a statement about the "appropriate size and purpose of national government" (Morgan, 2009, p. 7), expressions of

\footnotetext{
${ }^{4}$ Exceptions were FY1998-FY2001 during the Clinton presidency. We find that, since 1973, the average annual deficit as a share of gross domestic product (GDP) is virtually identical for Republican and Democratic administrations (see Fig. 7).
} 
concern about deficits have long been prominent among conservative Republicans. For example, such concern took on an even more urgent tone in the 2010s with the rise of the "Tea Party Patriots" movement. This is perhaps unsurprising given that a foundational component of conservative political ideology is that of fiscal responsibility, wherein the government restrains its spending to allow private markets to operate more freely (e.g., Feldman, 1988; Grossmann \& Hopkins, 2016, pp. 75-77; Lewis-Beck et al., 2008, pp. 208-209).

Yet, even if Republicans demonstrate relatively more concern about government overspending than do Democrats, all members of the public-regardless of party affiliation-generally view deficits negatively in an absolute sense ${ }^{5}$ (e.g., see Wood, 2004) and, thus, are unlikely to dramatically change their stance on the issue. ${ }^{6}$

Regarding citizens' perceived accountability for government overspending, as with various other macroeconomic outcomes, presidents are likely to be the ones ultimately held accountable (e.g., Kane, 2016; Newman, 2013; Sirin \& Villalobos, 2011). This implies that deficits will tend to function as a political liability for presidents and their respective parties. We theorize that such threats to each party's status and reputation-and thus citizens' own partisan identities-provide fertile ground upon which partisans may reason about the importance of deficits in a biased fashion.

\section{Partisan-Motivated Issue Attention and Government Overspending}

A wealth of literature demonstrates that partisanship guides citizens' attitudes about various political issues (Barber \& Pope, 2019; Cohen, 2003; Kinder \& Kalmoe, 2017; Mason, 2015). Recent work in political psychology has advanced a nuanced theory of partisan bias, wherein citizens balance a need to express partisan-motivated judgments against a desire to accurately evaluate current conditions (e.g., Bolsen et al., 2014; Leeper \& Slothuus, 2014).

These rival goals - accuracy and partisan bias-compete in the minds of partisans to produce over-time variation in the extent and direction of partisans' perceptual gaps about objective reality (Bisgaard, 2015; Dickerson \& Ondercin, 2017; Jerit \& Barabas, 2012). Much of the literature on this phenomenon has specifically analyzed partisans' retrospective economic evaluations (REEs), or overall views on recent economic performance (e.g. De Geus and Roosmarjin, 2019; Gerber \& Huber, 2009; Jones, 2019).

How might partisan bias shape public attitudes toward deficit spending? Again, partisans can draw different conclusions about objective conditions (see also Gaines

\footnotetext{
${ }^{5}$ Of course, these perceptions gloss over the many nuanced economic debates on the subject. Questions regarding the deficit-e.g., "how big is too big?" and "exactly when are deficits bad?" (e.g., see Heilbroner and Bernstein 1989; Krugman 2000)_are likely overlooked by the average voter.

6 We therefore regard government overspending as more akin to a valence issue than a "position issue," for which policy disagreement (as with crime and corruption) largely stems from particulars concerning how to address it vis-a-vis whether there should be less or more of it (e.g., Ansolabehere and Snyder 2000; Lewis-Beck et al., 2008, 195; Stokes 1963).
} 
et al., 2007). Indeed, research on government overspending has largely focused on gaps in Americans' beliefs about the deficit's size (Achen \& Bartels, 2016; Bullock et al., 2015). Kinder and Kalmoe (2017, pp. 112-13), for example, find that, despite the federal deficit having decreased in size between 1992 and 1996, Republicans were far more likely than Democrats to erroneously state that the size of the deficit had increased during this time (see also Meirick, 2016). Such biased perceptions of the deficit's size, therefore, vary according to citizens' party identification and the party of the president.

Alternatively, partisans may interpret real-world conditions correctly, yet attribute credit and blame in a systematically biased fashion (Rudolph, 2006; Zell, Stockus, \& Bernstein 2021). In doing so, partisans develop cognitively effortful justifications to defend their preferred partisan incumbents from accusations of economic mismanagement. For example, partisans might acknowledge that the budget deficit is expanding under an inparty president, yet assign blame for the development elsewhere (e.g., Congress, international factors, the outparty's obstructionism, etc.; see Bisgaard, 2019; Evans \& Pickup, 2010).

Building directly upon this literature, we argue that partisan bias likely extends beyond misperception of "the facts" and/or motivated attribution of responsibility. Representing an additional path for directional goals to shape political beliefs, our proposed theory of partisan-motivated issue attention (PMIA) states that partisans systematically adjust the importance they assign to issues based on the party presiding over those issues. In the realm of government overspending specifically, even if partisans loosely agree on the basic facts of the deficit (its size and growth over time), and similarly attribute responsibility for those facts to political figures (e.g., the president, the president's party, etc.), they can nevertheless satisfy partisan instincts by attenuating or augmenting the importance of deficit reduction as a policy priority.

Compared to the multitude of studies on the misperceptions of facts, a far smaller number have examined partisan bias in perceived issue importance (cf. Bisgaard \& Slothuus, 2018; Boninger et al., 1995; Mullinix, 2016; Slothuus \& de Vreese, 2010). Moreover, no studies to our knowledge have investigated perceived importance of U.S. government overspending in particular. ${ }^{7}$ In applying the logic of PMIA to this specific issue domain, we reason that partisans will be inclined to change the importance they assign to the issue of deficits, and that this perceived importance will vary systematically based upon which party presides over them via the presidency.

Partisan-Motivated Attention Hypothesis (H1) Partisans will adjust the importance of deficit spending based upon the party of the incumbent president.

\footnotetext{
7 One notable quasi-experimental study by Bisgaard and Slothuus (2018) leveraged a unique five-wave Danish panel survey from 2010-2011. The authors find that Danish Center-Right partisans altered perceptions of the budget deficit in response to explicit party cues, suggesting that partisans' perceived importance of current issues, including budget deficits, are responsive to elites and shift as a means of satisfying partisan instincts.
} 


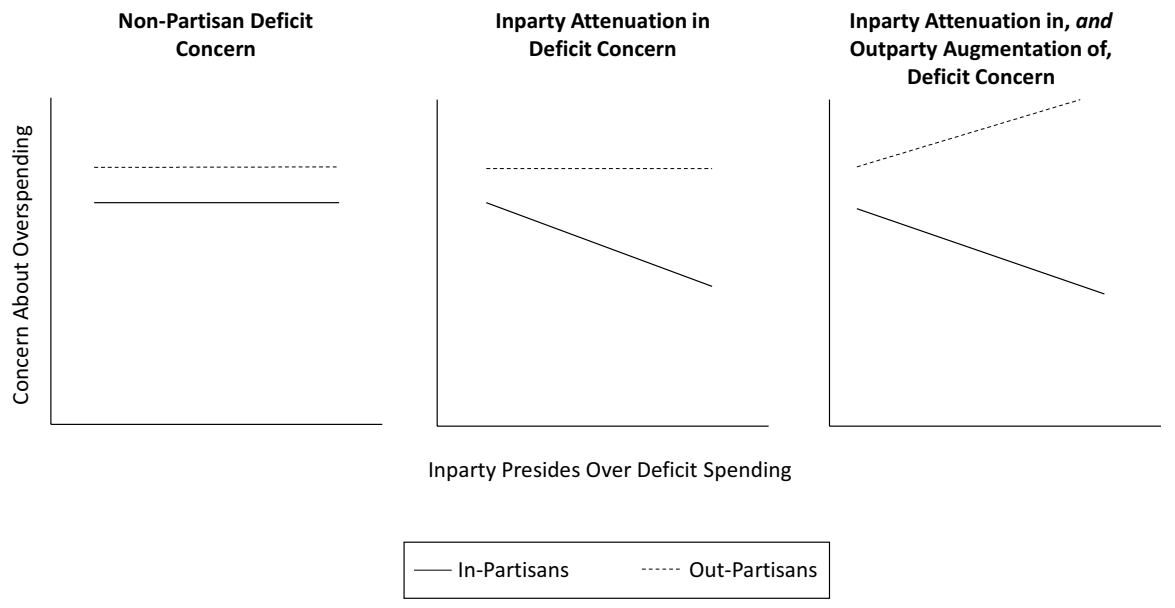

Fig. 1 Competing theoretical possibilities. Notes Panels display potential patterns in partisan bias on the issue of government overspending in light of a president overseeing deficit spending. Left panel indicates no partisan bias in perceived importance of deficit spending. Center panel is consistent with H1a but not H1b. Right panel is consistent with both H1a and H1b

Yet apart from the question of whether partisans exhibit bias in beliefs about the importance of overspending is the question of when this bias might occur-i.e., do partisans only lower the importance of deficit-spending when an inparty president is in power, or might they also believe deficit-spending is more important when an outparty president is in power? On one hand, the large literature on cognitive dissonance (Festinger, 1962) implies that, when an inparty president is in power, cognitive pressures will emerge to reduce the dissonance that arises from a positivelyviewed actor (the inparty president) engaging in a negative action (presiding over deficit-spending). Therefore, and consistent with social-psychological evidence that individuals engage in "trivialization" (see Simon et al., 1995), we hypothesize that, during instances of an inparty president overseeing deficit spending, the resultant cognitive dissonance can be reduced by reducing the importance of the issue:

Inparty Attenuation Hypothesis (H1a) Partisans will assign less importance to the issue of deficit spending when an inparty president is in power.

Along similar lines, it is possible that, whatever their baseline belief, partisans are also willing to systematically increase their perceived importance of government overspending when the outparty holds office. Partisans generally hold negative affective evaluations of members of the outparty (e.g., Mason, 2018), which would naturally include an outparty president. Thus, given that overspending is also viewed negatively, this compounding of negatively-charged considerations (e.g., Lodge \& Taber, 2013) likely stands to make overspending appear more problematic (i.e., more negative), and therefore in greater need of being quickly addressed. 
Outparty Augmentation Hypothesis (H1b) Partisans will assign greater importance to the issue of deficit spending when an outparty president is in power.

To visually illustrate this variety of theoretical possibilities, Fig. 1 presents three distinct scenarios. The left panel is akin to a null hypothesis wherein, as a new presidential administration begins overseeing deficit spending (see $x$-axis), there is no discernible change in how members of either party regard the importance of overspending (see $y$-axis). The center panel, in contrast, is consistent with H1a but not H1b: inparty members reduce cognitive dissonance via lowering the importance of overspending, while outparty members exhibit no change. The right panel is consistent with both H1a as well as H1b: inparty members systematically lower, but outparty members systematically increase, the perceived importance of deficit-spending.

\section{Survey Experiments}

To test H1, we first fielded a survey experiment on Amazon.com's MTurk (e.g., Thomas \& Clifford, 2017) in January of $2020(n=1024)$, followed by a larger, preregistered experiment via Lucid (see Coppock \& McClellan, 2019) in February of $2020(n=5034) .{ }^{8}$ While the former is a convenience sample of U.S. adults, the latter study included quotas to obtain a sample that is nationally representative in terms of age, gender, race/ethnicity, and geographic region (see Supplemental Appendix for demographic information about each sample).

The basic features of the two experiments were nearly identical. Respondents were instructed that they would be reading "a brief excerpt from a forthcoming study of government spending over the past 45 years." Respondents were also informed that this (fictitious) study excerpt had been "completed by a variety of professional economists, university researchers, and government analysts." The surveys "blocked" on party identification (Gerber \& Green, 2012, pp. 71-79), which was measured at the start of the survey using the canonical 7-point scale ranging from "Strong Democrat" to "Strong Republican" (see Supplemental Appendix). We then randomly assigned each (blocked) respondent to read one particular version of the study (see Table 1). The key manipulation is whether the study exclusively focuses on Democratic or Republican presidents. For partisans, the experimental manipulation is thus designed to assign responsibility for deficit spending and debt to one's preferred party (i.e., inparty) or one's non-preferred party (i.e., outparty). ${ }^{9}$ Other elements of the vignette-e.g., the long-term average level of deficit-spending, the

\footnotetext{
8 The Lucid study was pre-registered using the Open Science Framework in February of 2020, available at the following link: https://osf.io/smr6g

9 As the vignettes were more than 800 words in total, manipulating only these two words ("Democratic" and "Republican") minimizes the risk of confounding (Dafoe, Zhang, and Caughey 2018).
} 
Table 1 Experimental vignette wording
Vignette text assigned to respondent

$\begin{array}{cl}\begin{array}{c}\text { Study title and } \\ \text { topline }\end{array} & \text { Government Spending and Deficits Under } \\ & \text { [Democratic/Republican] Presidents: }\end{array}$

Every [Democratic/Republican] president ran a budget deficit during their time in office, our analysis found. On average, [Democratic/Republican] presidents spent around $13.5 \%$ more each year than the federal government took in.

Body of study Government spending is an issue that we often excerpt hear about in the United States. While different presidents have different policy priorities, our analysis of [Democratic/Republican] presidents finds several noteworthy consistencies across the 45-year period of 1973 to 2018 (the most recent year for which we were able to obtain data).

The majority of federal government spending is on social programs and national defense. [Democratic/Republican] presidents, on average, oversaw approximately $75 \%$ of the federal budget being spent on social programs (mainly Social Security, Medicare, and Medicaid, and to a lesser extent other spending on veterans, the poor and the disabled). Approximately $16 \%$ of these presidents' budgets were dedicated to defense-related spending.

However, on average, government spending during these [Democratic/Republican] presidencies substantially exceeded revenue. In fact, [Democratic/Republican] presidents since 1973 spent, on average, $13.5 \%$ more each year than the federal government took in. This means that for every $\$ 100$ that [Democratic/Republican] presidents collected in revenue each year, they oversaw $\$ 113.50$ being spent.

With [Democratic/Republican] presidents having consistently run budget deficits over many years, this has resulted in a steady increase in the national debt, which is the total amount of money owed by the federal government. Again, we find this pattern of increasing the national debt to be remarkably consistent among [Democratic/Republican] presidents since 1973.

Text within brackets represents experimentally manipulated text in the MTurk and Lucid studies. 


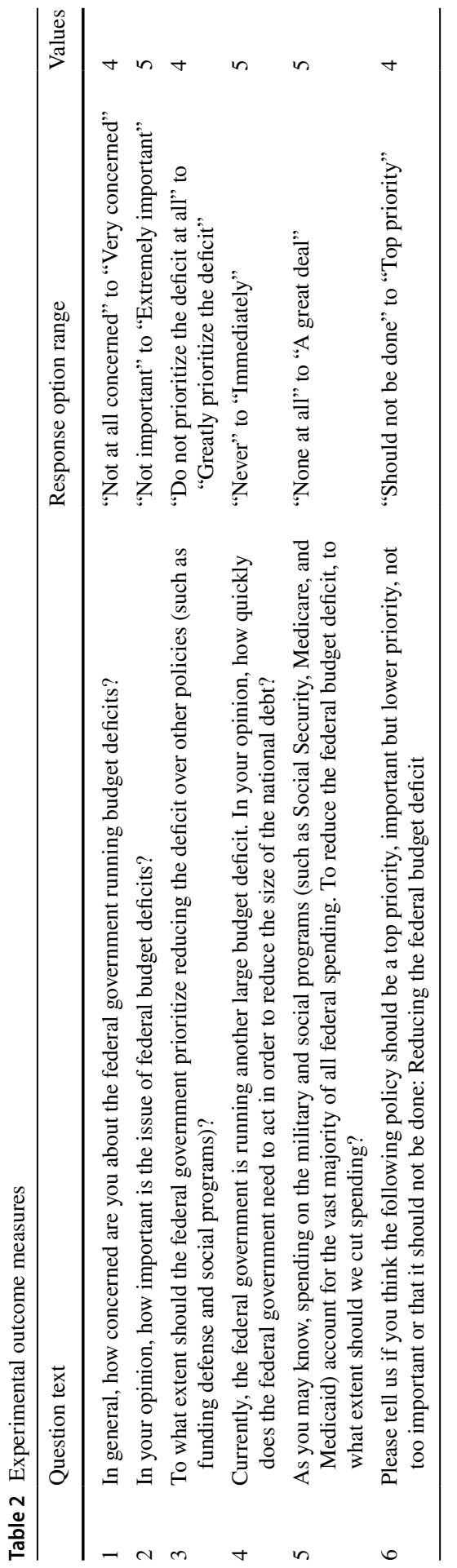


average budget allocations dedicated to social programs and national defenseremained identical across conditions. ${ }^{10}$ In this way, our design minimizes the possibility of unintentional confounding whereby, for example, comparing Democratic and Republican presidents may also cue beliefs about how the two parties differ on social welfare and military spending (see Dafoe et al., 2018). A variety of post-outcome manipulation checks (Kane \& Barabas, 2019) confirm these treatments were attended to and functioned as intended (see Supplemental Appendix).

Following the experimental vignette, respondents answered a total of six items designed to gauge perceived importance of the deficit. The wording of these various items, as well as information about the response options, are featured in Table 2. Collectively, these survey items measured the extent to which the federal deficit (and debt) is perceived as a problem in itself and, similarly, as a problem that needs to be quickly addressed by policymakers. In both the MTurk and Lucid studies, these items had positive and statistically significant $(p<0.05)$ pairwise correlations, with Cronbach's alpha $(\alpha)$ values of 0.83 in the MTurk study and 0.80 in the Lucid study. As such, we combined these items into a single scale (Deficit Importance) ranging from 0 to 1 , with higher values indicating greater perceived importance of deficit spending as an issue and the need to address it. ${ }^{11}$

\section{Experimental Results}

We first present the results of the MTurk study. ${ }^{12}$ The $y$-axes of Fig. 2 indicate the mean values of Deficit Importance. The left portion of Fig. 2 (Panel A) displays these means (with 95\% CIs) for partisans across each of the two experimental conditions. Democratic (Republican) respondents who read the "Democratic (Republican) presidents" version of the experimental treatment are featured in the "Inparty Presidents" column, while Democrats (Republicans) who read the Republican (Democratic) vignettes are included in the "Outparty Presidents" column.

As the left portion of Panel A in Fig. 2 reveals, moving from a report about inparty presidents to a report about outparty presidents yields a substantial increase in Deficit Importance. This effect slightly exceeded 5 percentage points on the 0 to 1 scale $(p<0.001)$. Subsequent analyses confirmed that Democrats and Republicans responded in a similar fashion to the manipulation, with Democrats (Republicans) exhibiting a treatment effect equal to 5.7 (4.7) percentage points. There was a nonsignificant interaction between the manipulation and respondents' party identification $(p=0.71)$.

We further investigated the effects of partisanship by stratifying the sample across (1) identification with a party, and (2) party identification strength. First, we examined whether "pure" Independents show significant differences when reading about deficits under Democratic (versus Republican) presidents. Because pure Independents lack a psychological attachment to one particular party, and thus have little

\footnotetext{
${ }^{10}$ To enable the (fictitious) report to be as believable as possible, we based the purported level of deficit spending (13.5\%) on the actual average according to Federal Reserve data. Similarly, we based social welfare and health spending on reports of current levels (see Jacobson 2015).

${ }^{11}$ Details regarding the wording of all response options can be found in the Supplemental Appendix.

${ }^{12}$ Underlying regression model output can be found in the Supplemental Appendix.
} 

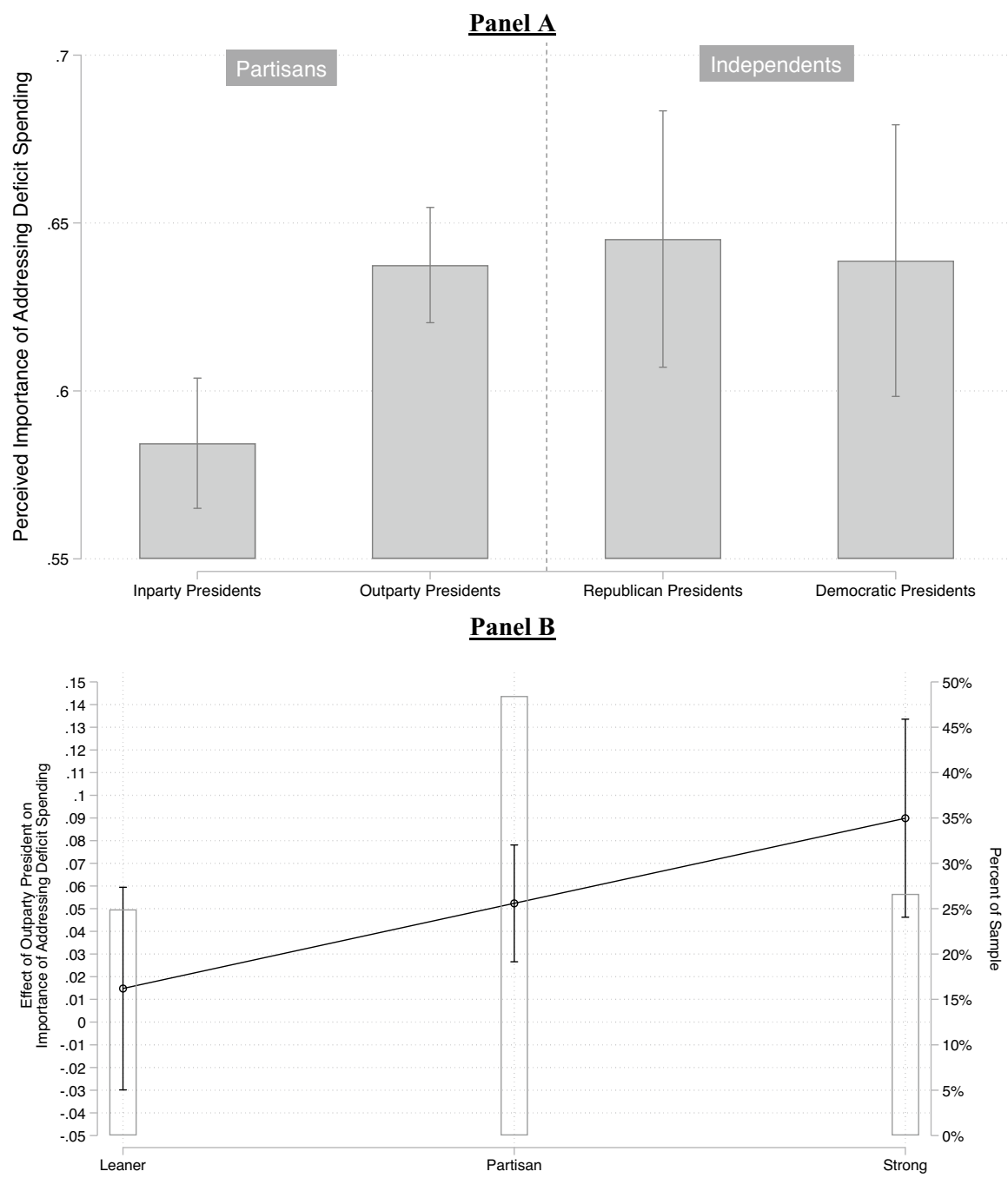

Fig. 2 Partisanship and importance of government overspending (MTurk). Notes Dependent variable is a six-item additive scale, with higher values indicating greater perceived importance of addressing budget deficits. Panel B's $y$-axis shows treatment effect of "Outparty presidents" treatment relative to "Inparty presidents" treatment; right $y$-axis displays share of each partisan group in the sample. 95\% CIs shown. MTurk data (total $\mathrm{N}=1024$ )

reason to exhibit partisan bias (e.g., Lavine, Johnston, and Steenbergen 2012), the importance they assign to addressing the deficit should be relatively unaffected by which party appears to preside over it. Indeed, as the right portion of Fig. 2 (Panel 

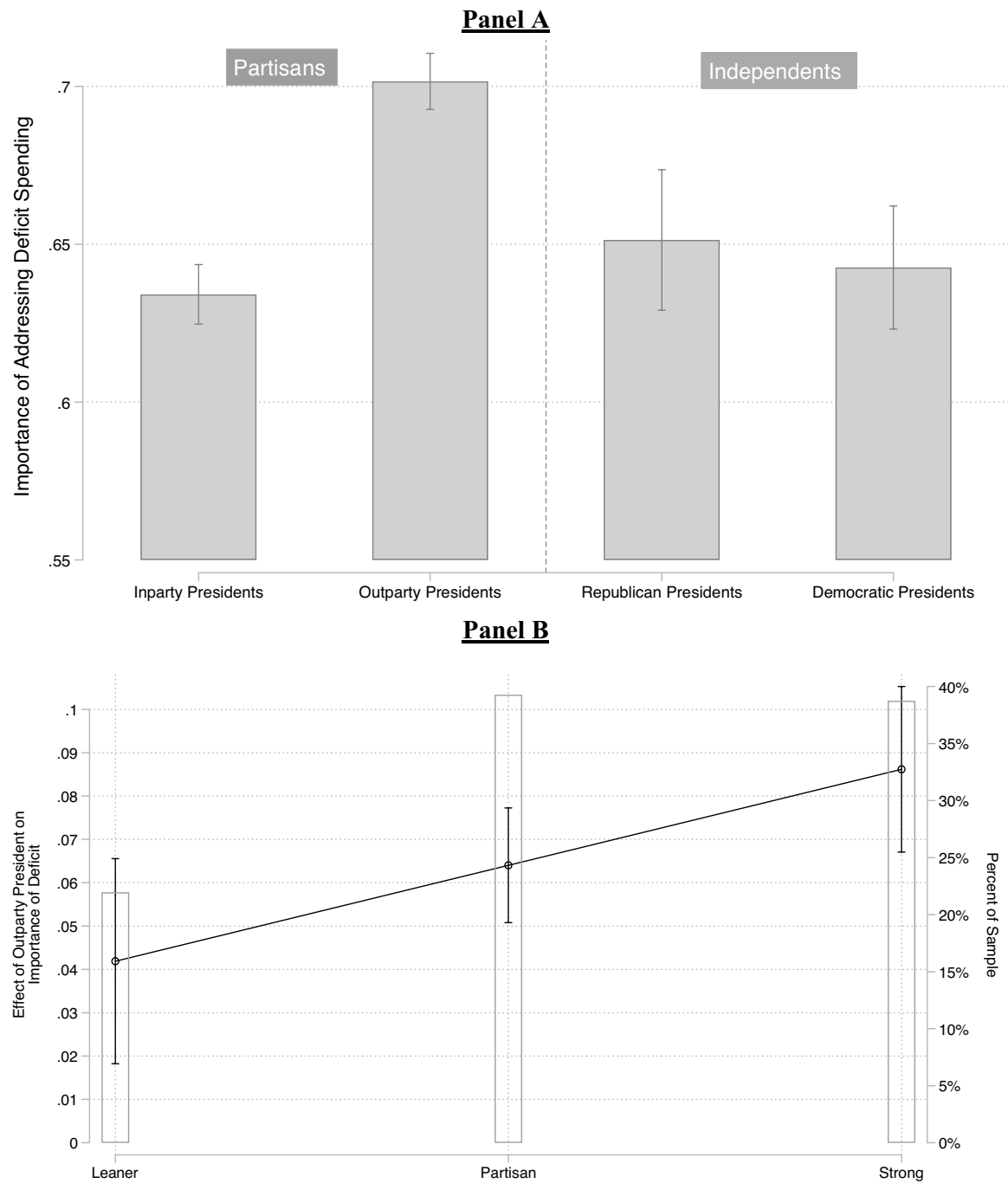

Fig. 3 Partisanship and importance of government overspending (Lucid). Notes Dependent variable is a six-item additive scale, with higher values indicating greater perceived importance of addressing budget deficits. Panel B's $y$-axis shows treatment effect of "Outparty presidents" treatment relative to "Inparty presidents" treatment; right $y$-axis displays share of each partisan group in the sample. 95\% CIs shown. Lucid data (total $\mathrm{N}=5034)$

A) indicates, Independents exhibited virtually identical scores on the Deficit Importance scale regardless of which party they read about $(p=0.82)$.

Next, if partisan bias is indeed the key mechanism underlying these results, it stands to reason that partisans with stronger attachment to their party will be more inclined to engage in motivated reasoning, and thus exhibit stronger treatment effects. As shown in Panel B of Fig. 2, we indeed find a positive, significant 


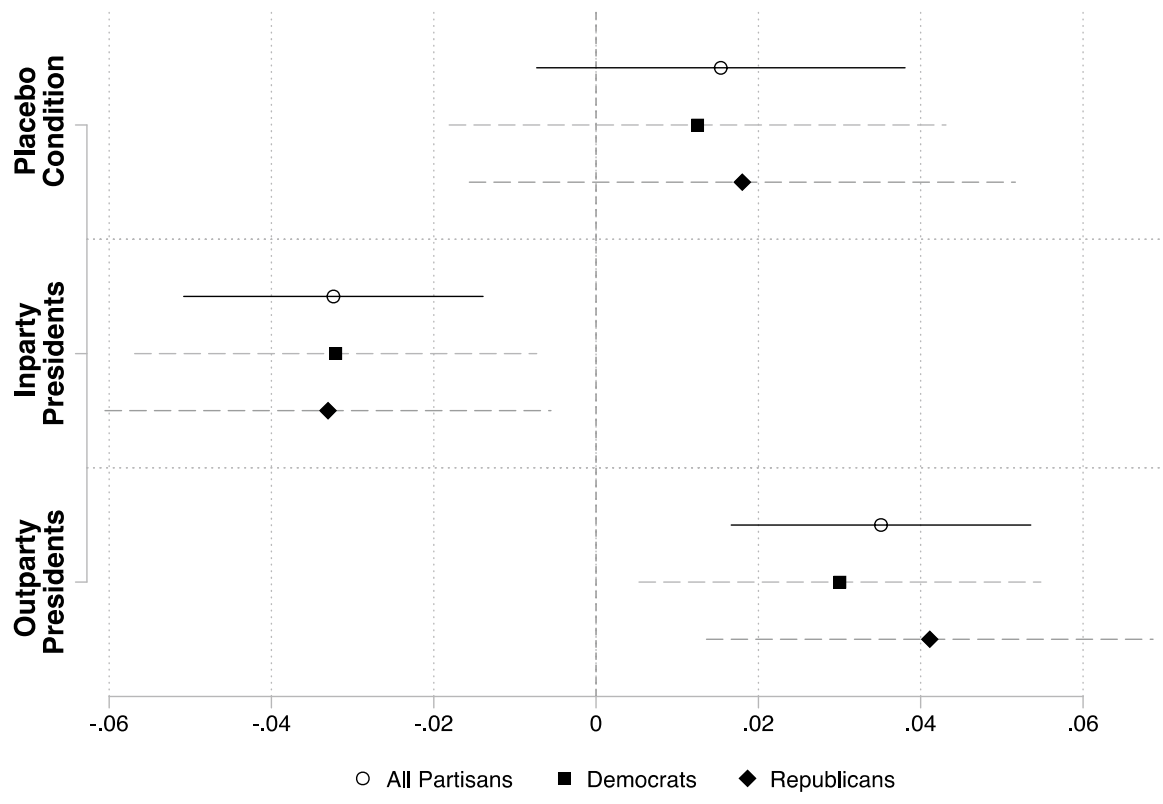

Fig. 4 Treatment effects involve both offensive and defensive mechanisms (Lucid). Notes Dependent variable is a six-item additive scale, with higher values indicating greater perceived importance of addressing budget deficits. The $x$-axis displays the treatment effect of a given experimental condition. Excluded experimental condition is a pure control condition (i.e., respondents were not given any information). "Placebo condition" discussed "all presidents" rather than presidents of one party. 95\% CIs shown. Lucid data (total $\mathrm{N}=5034)$

interaction between the treatment and party identification strength $(p<0.05)$, with the strongest partisans exhibiting a predicted treatment effect of 9 percentage points on the Deficit Importance scale. ${ }^{13}$ The MTurk study results thus provide strong initial support for the partisan-motivated attention hypothesis $(\mathbf{H 1})$.

Turning now to the pre-registered Lucid study, the pattern of results is strikingly similar to that of the previous experiment. As Fig. 3 (Panel A) shows, partisans assigned greater importance to addressing deficit spending when reading about outparty (versus inparty) presidents. This effect was approximately 7 percentage points (an $11 \%$ increase; $p<0.001$ ). Subsequent analyses again found that Democrats and Republicans exhibited markedly similar effects $(0.06$ and 0.07 , respectively, with a non-significant interaction between the experimental manipulation and party identification; $p=0.36$ ). As shown in Fig. 3 (Panel A), Independents again showed no significant difference in Deficit Importance across conditions $(p=0.56)$. Lastly, Panel B of Fig. 3 demonstrates that treatment effects significantly increased with partisan strength $(p<0.05)$, with the strongest partisans exhibiting a predicted treatment effect of nearly 9 percentage points on the Deficit Importance scale.

\footnotetext{
${ }^{13}$ The right $y$-axis of this graph indicates the share of respondents falling into each of the three categories of partisan strength.
} 


\section{Investigating Mechanisms}

To better understand the precise mechanisms underlying the results above, the Lucid study featured two additional control conditions. These conditions comprise $25 \%$ of the total sample $(n=1,269)$. One condition was a "pure control," in which respondents were not assigned to view any vignette, instead proceeding directly to the outcome measures. The other condition served as a "placebo control," in which respondents were shown a vignette with non-partisan language ("all presidents") instead of partisan language ("[Democratic/Republican] presidents"). In effect, this design choice enables us to determine whether empirical evidence exists for H1a as well as H1b or, conversely, if the effects we observe above are primarily due to only one of these hypotheses being correct.

Figure 4 plots OLS regression coefficients (with 95\% CIs) for the placebo and two main experimental conditions relative to the pure control condition (which functions as the excluded category), with Deficit Importance specified as the dependent variable. Coefficients appear for all partisans, as well as for Democrats and Republicans separately. The figure illustrates, first, that Democratic and Republican respondents exhibited markedly similar treatment effects. Second, likely owing to its explicit discussion of deficit spending, the placebo condition had a slightly positive effect on Deficit Importance (relative to the pure control condition), though this effect was not statistically significant $(p=0.18)$. Third, relative to the pure control, the "inparty presidents" and "outparty presidents" treatments have roughly symmetric effects: the former lowered Deficit Importance by 3.2 percentage points $(p<0.001)$, while the latter increased Deficit Importance by 3.5 percentage points $(p<0.001)$. However, relative to the placebo control, the main effect observed above appears to be driven somewhat more by inparty (H1a), rather than outparty (H1b), considerations: the former effect is 4.8 percentage points $(p<0.001)$, while the latter is only 2.0 percentage points $(p<0.05)$.

Consistent with the right panel of Fig. 1, these results reveal that two distinct mechanisms underlie the main effects observed above. Specifically, partisans (1) lower Deficit Importance when an inparty president is responsible, as well as (2) increase Deficit Importance when an outparty president is responsible. In both cases, then, partisan bias systematically guides citizens' perceived importance of the deficit, even in the absence of explicit elite cues to do so, and with Democrats and Republicans being nearly equally susceptible to such partisan instincts. 


\section{Observational Data}

The previous section found consistent experimental evidence for H1, both among Democrats as well as Republicans. Yet to what extent do we observe such effects amid the myriad cues and distractions that exist in the real world? To investigate this question, we draw upon two separate data sets, both of which leverage the federal transfer of power from the (Democratic) Obama Administration to the (Republican) Trump Administration in January of 2017.

The first data set includes two separate Pew Research Center (PRC) samples, one interviewed in January of 2016 and the other interviewed in January of 2018. ${ }^{14}$ These were randomly selected, nationally representative samples of adults residing in the United States (total $n$ used in the analysis=1,545). We selected these two surveys based upon (1) their proximity to the change in presidential administrations, and (2) the inclusion of the same measure of concern regarding deficit spending. Specifically, respondents were asked to indicate the degree to which, for the current president and Congress, "Reducing the budget deficit" should be a "Top priority", "Important but lower priority", "Not too important", or "Should not be done". Because over $50 \%$ of the sample selected "Top priority", we dichotomized this variable such that $1=$ "Top priority", and $0=$ any other response, to simplify the analyses below. ${ }^{15}$ This binary outcome measure serves as our dependent variable of interest for the PRC analyses.

The second data set comes from the Democracy Fund's "Voter Study Group" (VSG) 2019 panel data set. The VSG includes nearly 8,000 respondents, repeatedly interviewed (online) in late 2016 (during the Obama presidency), July of 2017 (early in the Trump presidency), and again in January of 2019 (later in the Trump presidency), yielding a total $n$ size of nearly 20,000 for our analysis. ${ }^{16}$ In each of these waves, respondents were asked to rate the importance of various issues, including "the budget deficit." Respondents could rate the budget deficit as "Very important", "Somewhat important", "Not very important", "Unimportant", or, in rare cases (less than $2 \%$ in any given wave) voluntary decline to answer. Similar to the PRC data, over $50 \%$ of the sample indicated that the budget deficit is a "very important" issue. Thus, we again created a dichotomous variable for which $1=$ "Very important" and $0=$ any other response. This serves as our dependent variable for the VSG analyses.

\section{Results}

If partisans reason about the importance of government overspending in a biased fashion, as per H1, the change in presidential administrations should spur changes in

\footnotetext{
14 Details concerning the sampling and interview methodology can be found in the Supplemental Appendix.

15 As discussed below, we specify logistic regression models; however, the pattern of results remains the same when treating the scale as ordinal and specifying an ordered logistic model (see Supplemental Appendix).

16 See Supplemental Appendix G for further information regarding these data sets.
} 

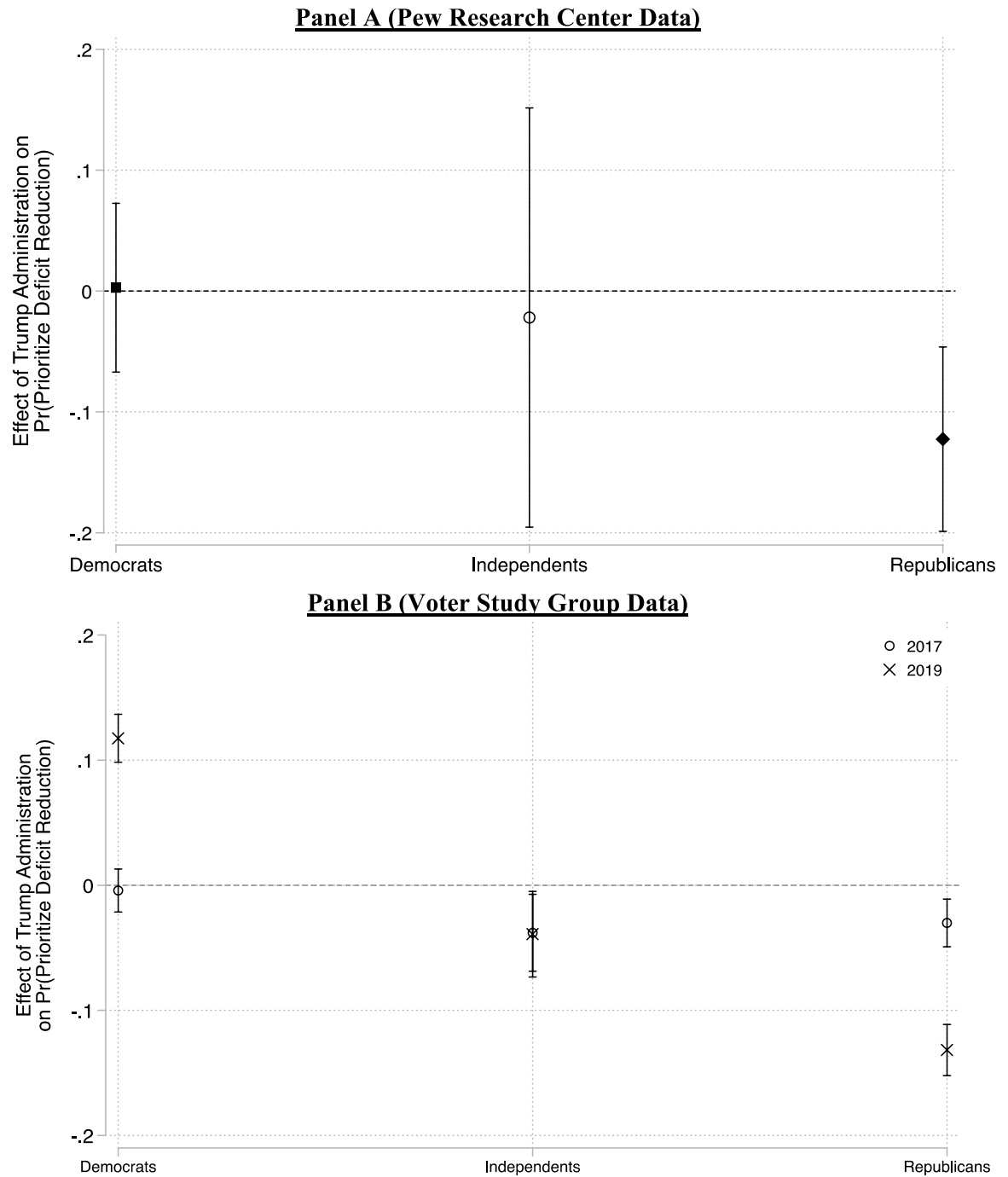

Fig. 5 Change in presidential administrations and importance of addressing deficit. Notes Dependent variable coded 1 = "reducing the budget deficit... is a top priority" (PRC)/"addressing budget deficit is... very important" (VSG), and coded 0 otherwise. PRC data from 2016 and 2018; VSG data are panel data collected in 2016 (baseline year), 2017 and 2019. The $y$-axis of both figures displays effect of changing from Obama Administration (2016) to Trump Administration on the dependent variable, while $x$-axis displays these estimates for each partisan group. $\mathrm{N}=1545$ (PRC) and 19,559 (VSG) 
partisans' perceived importance of addressing the deficit. Specifically, according to H1a and H1b, the change from the Obama Administration to Trump Administration should result in lower perceived importance of the deficit among Republicans and greater perceived importance of the deficit among Democrats, respectively.

To test these expectations using the PRC data, we specified a logistic regression model featuring an interaction between a trichotomous categorical measure of party identification (Democrat, Independent, or Republican) and the year of the survey $(0=2016,1=2018)$. To account for any potential imbalances between the two samples, we also included controls for respondents' age, family income, education level, gender identification, racial identification, and ideological self-placement. ${ }^{17}$

The results of this analysis are featured in the top panel of Fig. 5. The $y$-axis displays the marginal effect of changing from the Obama Administration (i.e., the 2016 survey) to the Trump Administration (i.e., the 2018 survey) on the probability of identifying "reducing the deficit" as a top public policy priority. For Republicans, moving from the Obama Administration to the Trump Administration predicts a more than 12 percentage-point reduction in the probability of identifying deficit reduction as a top priority $(p<0.01)$. Remarkably, we observe this effect despite only two years having elapsed since the first survey and, perhaps even more importantly, the fact that the budget deficit had actually increased each fiscal year, resulting in an even larger national debt in 2018 than in $2016 .^{18}$

In contrast, among Democrats, Fig. 5 shows the estimated effect to be nearly zero $(p=0.94)$, indicating essentially no change in perceived importance of deficits compared to 2016. The same is true of Independents, who exhibited a small, non-significant negative effect $(p=0.81)$. Thus, Fig. 5 provides additional evidence for H1a, though, in contrast to the experimental results, no evidence for $\mathbf{H 1 b}$.

We employ a similar methodological approach in examining the VSG panel data. Specifically, we specified a logistic regression model featuring an interaction between a trichotomous categorical measure of party identification (measured in 2016, the baseline wave) and a categorical measure of the three survey waves (2016, 2017, and 2019), with standard errors clustered by respondent.

Panel B of Fig. 5 displays the results of this analysis. Like Panel A, the $y$-axis in Panel B indicates the marginal effect of changing from the Obama to Trump administrations on the probability of identifying the budget deficit as a "Very important" issue. Beginning first with the effect of moving from the baseline year (2016) to 2017 (indicated by the hollow circles), we see that Republicans show a significant decrease in perceived importance, on the order of 3 percentage points $(p<0.001)$. Democrats, on the other hand, again showed a near-zero change in perceived importance of the deficit $(p=0.63)$. However, if we treat Independents essentially as a baseline (given that they have less reason to engage in partisan-motivated reasoning), it implies that the negative effect observed among Republicans in 2017 was not

\footnotetext{
17 Details regarding question/response wording, as well as descriptive statistics, for these variables (in both the PRC and VSG analyses) can be found in the Supplemental Appendix along with regression model output.

18 See Federal Reserve data located here: https://fred.stlouisfed.org/series/FYFSD.
} 
due to partisan bias but, perhaps, to other non-partisan considerations that were also on the minds of political Independents.

Far more dramatic, however, are the results for 2019 (indicated by the " $\mathrm{x}$ " symbols in Fig. 5). While we observe essentially the same result among Independents, we see that, compared to 2016, the probability that Republicans viewed the deficit as "Very important" decreased by more than 13 percentage points $(p<0.001)$. In this case, however, we also observe a marked increase in perceived deficit importance among Democrats, and of nearly identical magnitude: over the same span of time, Democrats exhibited a nearly 12 percentage-point increase in perceived deficit importance $(p<0.001)$. These patterns are precisely in line with both H1a and H1b, respectively, and strongly suggests partisan bias shapes beliefs about the importance of addressing the federal deficit, both among both Republicans and Democrats.

Thus, across the PRC and VSG data sets, we find strong evidence in support of H1. It is important to emphasize, again, that over the time frame we analyzed, both deficits and the total amount of government debt increased. This renders the existence of partisan bias all the more notable-perhaps especially in the case of Republicans, who clearly decreased perceived importance-insofar as it requires, at least to some extent, disregard for changes in objective reality. These findings therefore also accord with those of Crosby and Holbrook (2019), who find that public support for a balanced budget amendment is not significantly related to the actual size of deficits or levels of debt.

In sum, our experimental results above demonstrate that even without explicit cues from partisan elites, partisans in the mass public can reason about the importance of deficit spending in a biased fashion. Notably, the results of our observational studies display even larger effects than did our experiments. This may potentially be because elite partisan cues are also present, further fueling biases among partisans in the mass public. Thus, the observational data analyses raise the question of whether partisan news media might elevate (or downplay) government overspending as an important issue. To the extent such agenda-setting occurs (e.g., Boydstun, 2013), it could help account for some of the sizable shifts in attention to overspending that we observe among partisans in the mass public. Evidence of such efforts would also indicate that, along with citizens, elites operating in partisan media similarly alter attention to the issue of overspending in a partisan-biased fashion. To explore these questions further, in our final section we turn to a large-scale text analysis of televised partisan news media.

\section{Analyses of Partisan Media}

Applied to the partisan media context, H1 predicts that media mentions of the deficit should vary depending upon the party of the incumbent president. Specifically, mentions should be more frequent on Republican-oriented (Democratic-oriented) programs when a Democratic (Republican) president is in power.

To investigate these expectations, we performed both automated and manual content analyses of the FOX News Network's Hannity television show and MSNBC's The Rachel Maddow Show. These programs were chosen due to their relatively long 


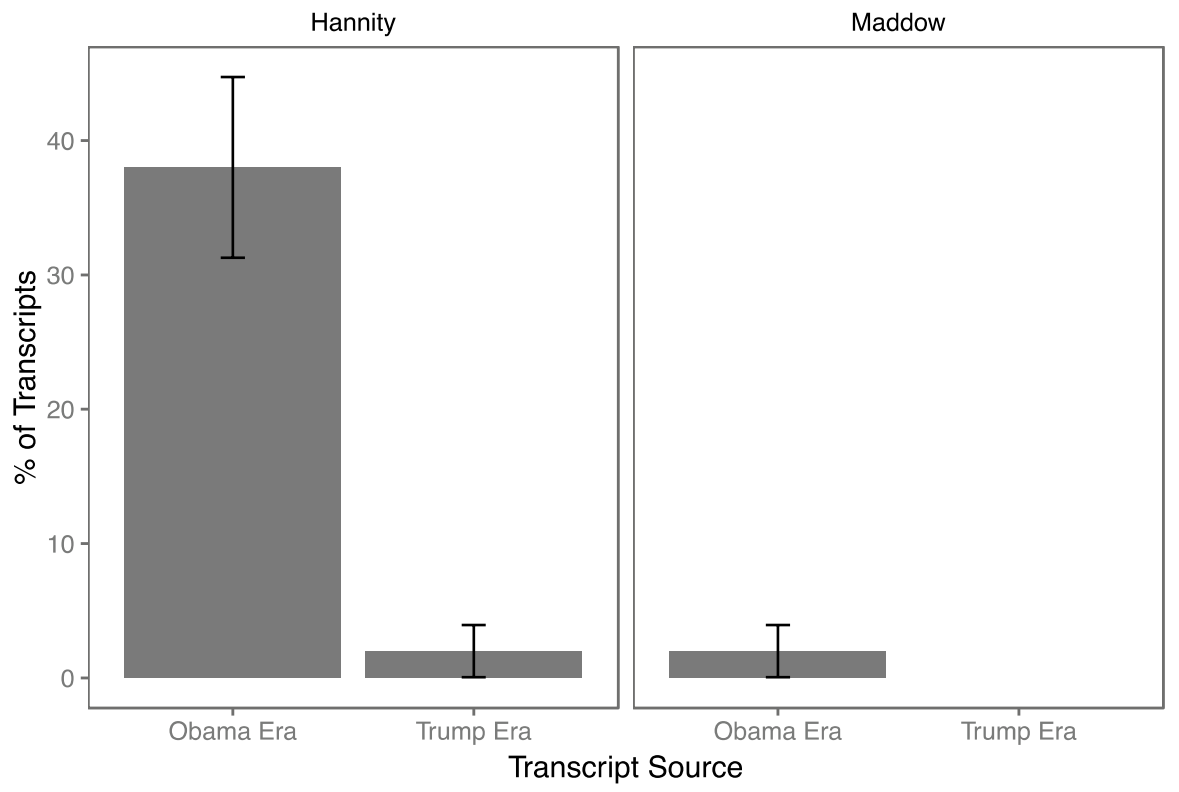

Fig. 6 Percent of hand-coded transcripts containing at least one explicit debt/deficit attribution to incumbent president, Hannity vs. the Rachel Maddow show. Notes Overall N = 200; Each of the four columns in this figure represent findings from 50 randomly selected transcripts from each administration/network pairing. As texts were randomly selected, they are distributed across the two time periods reflected in the columns of each facet relatively uniformly. 95\% CIs shown (calculated based upon binomial distribution to prevent overlap with 0 )

runs on two of the most prominent partisan media sources in U.S. media (e.g., Coe et al., 2008). We obtained a sample of transcripts of both shows from the Nexis Uni database, downloading all available full-text records from the platform for the period spanning the entire Obama administration and the Trump administration up to April 21, 2020 (when initial analysis was performed). This procedure yielded 4499 unique transcripts from the two news programs. The Supplemental Appendix describes how we selected texts that mentioned budget deficits and the national debt. It also includes a confusion matrix demonstrating the validity of the approach. Our strategy relied upon simple tools: we used string matches to identify mentions of the words "deficit(s)" and "debt", and then eliminated as many false positives as possible by parsing the linguistic context of each mention.

\section{Hand-Coded Analysis of Debt and Deficit Mentions}

Media attention to overspending may occur for a variety of reasons. While the full results of our automated content analysis can be seen in the Supplemental Appendix, our primary interest was the context of each mention of budget deficits and the national debt. To directly address H1, we employ a manual content analysis of a random subset of 200 transcripts. This sample contained 100 Maddow and 100 
Hannity transcripts evenly divided across the Obama and Trump administrations. We employed a simple binary coding strategy that identified whether the federal debt or deficit was mentioned $(1=$ Yes, $0=$ No), and whether responsibility attributions targeted either the incumbent (1) or any other source, including past presidents (0). This coding strategy allows us to identify the proportion of transcripts for which there was at least one clear mention of overspending that also attributed responsibility to the sitting president, across presidential administration and transcript sources. Our coders' interrater reliability scores were strong: we report a Cohen's Kappa of 0.91 for the existence of a debt/deficit mention $(p<0.01)$ and a Cohen's Kappa of $0.82(p<0.01)$ for the responsibility attribution measure.

The results of this analysis are presented in Fig. 6. The height of the bars in this figure represent the overall percentage of transcripts attributing responsibility for overspending to the sitting president. As this figure reveals, we find clear evidence that Hannity made many explicit attributions of responsibility to Obama during his time in office. However, echoing the results of the automated analysis (see the Supplemental Appendix), the same was not true of Hannity during the Trump administration, wherein mentions became dramatically less frequent: explicit responsibility attributions declined from $38 \%$ of coded transcripts to a mere $2 \%$ of coded transcripts after the change in administration $(p<0.01) .{ }^{19}$ Again, this pattern is fully consistent with H1a.

In contrast, Maddow explicitly blames the incumbent $2 \%$ of the time during the Obama administration, yet not at all in our subsample spanning the Trump administration. The rate of mentions across the periods on Maddow is statistically indistinguishable from zero in both presidential administrations. In contrast to Hannity, the results for Maddow are inconsistent with H1b: Maddow's discussion is almost never centered on the incumbent's responsibility for developments in those realms, regardless of which party occupies the presidency.

The present analysis suggests that on left-leaning cable television, the party of the president has relatively little effect on discourse surrounding the national debt and federal budget deficits. In contrast, right-leaning partisan media transmit explicit responsibility attributions for debt and deficit issues under Democratic presidents, yet this tendency nearly vanishes when a Republican occupies the White House. Our results thus confirm that, like partisans in the mass public, elites operating in partisan mass media also systematically adjust attention to deficits based on the party of the president. However, in this case, we do find a substantial asymmetry in how partisan media communicate about government overspending to the American public, with conservative media more inclined to adjust attention to deficits than liberal media.

\footnotetext{
${ }^{19}$ This is an especially notable finding given that the passage of the unprecedentedly massive $\$ 2$ trillion COVID-19 stimulus package (in the Spring of 2020) was included in our analysis.
} 


\section{Discussion and Conclusion}

Numerous literatures have emphasized the ways in which partisan attachment affects citizens' issue stances, factual beliefs, and attribution of responsibility. In this article, we propose a theory of partisan-motivated issue attention (PMIA), which contends that partisan attachment can also systematically affect the importance that one assigns to a given public policy issue. Such bias can enable citizens to satisfy partisan psychological pressures by changing the degree to which they regard an issue as one that needs to be prioritized and addressed. We apply this argument to the particular issue domain of government overspending.

In positioning the party of the president as a key contextual factor that enables partisan bias to occur, our study finds that across presidential administrations, partisans' attention to the budget deficits varies both substantially and predictably. When one's own party occupies the White House, partisans' attention to overspending declines. Yet we also find that when the outparty occupies the presidency, partisans' attention to overspending increases. Our study contributes to the literature on bias by highlighting attenuated concern and augmented concern as two distinct pathways through which partisans readily adjust their beliefs about government overspending.

It is worth highlighting that, because there exist several alternative pathways for partisans to behave in a biased fashion, our tests are likely somewhat conservative. Theoretically, partisans could satisfy their need for congenial interpretations of reality without adjusting the importance of government overspending, e.g., by believing the deficit to be smaller than it is reported to be, and/or by rationalizing the attribution of blame for deficits to someone (or something) else rather than to their inparty presidents. That our findings show substantial evidence of bias in perceived issue importance, therefore, underscores the power and adaptability of partisan bias as a psychological phenomenon in contemporary American politics.

We do caution, however, that while we find systematic bias in perceived importance of overspending, citizens' concerns about deficits do not ever completely vanish, regardless of which party controls the presidency. ${ }^{20}$ That said, our findings reveal surprisingly symmetrical effects across Republican and Democratic party identifiers. This symmetry is especially notable given the Republican Party's more overt commitment to fiscal conservatism.

Our study also makes an important contribution to recent debates about the sources of bias in citizens' perceptions. Previous research treats cues from partisan elites as central drivers in shaping partisans' beliefs about deficits and their consequences (e.g., Bisgaard \& Slothuus, 2018). In contrast, our study suggests that partisan bias can occur even among partisans who have not been exposed to framing efforts from partisan elites. Democrats, whose aligned media (in this case represented by Rachel Maddow) rarely mentioned deficits after Trump assumed office,

\footnotetext{
${ }^{20}$ In some cases (e.g., the VSG panel data) Republicans were more concerned about the deficit than Democrats regardless of which party held the presidency. However, in the Lucid experimental data, partisan groups were nearly at parity.
} 
nevertheless adjust their perceived importance of deficits (as shown in the observational analyses). Thus, partisan bias on the issue of government overspending may be exacerbated by partisan-elite cues, but, even in the absence of such cues, the underlying psychological process nevertheless leads partisans to react in predictable ways as presidential power changes hands.

Though future research is needed, we believe that PMIA is likely to generalize to a variety of so-called "valence issues"-i.e., issues for which a given outcome is generally accepted as being positive or negative (e.g., high crime rates, low gas prices, high inflation, etc.), particularly when one party can be plausibly viewed as responsible for it (e.g., via the presidency). This is largely because partisans' ability to change positions on such issues is constrained (e.g., inparty members are unlikely to rationalize high inflation as a political accomplishment). ${ }^{21}$ That said, future research would also do well to integrate our theory with research on issue ownership (Egan, 2013). For example, it may be the case that partisans show the largest changes in perceived importance on issues that are generally "owned" (versus not owned) by one party. Inparty (outparty) members may be especially motivated, in such cases, to attenuate (augment) the importance of a negative outcome because of the potential reputational consequences of under-performing on an issue that, in part, defines the inparty.

Finally, our findings complicate theories of presidential accountability. With respect to addressing the deficit, it is unsurprising that presidents might opt to "kick the can" instead of resolving shortfalls via unpopular policies such as tax increases or spending cuts. Logically, this willingness to ignore deficits should render presidents more vulnerable to political attacks. Yet if partisans systematically adjust the importance they assign to issues, it potentially undermines the extent to which presidents need to be responsive to public preferences for deficit reduction while seeking to accomplish various policy ends. In the extreme, presidents could (somewhat justifiably) dismiss deficit-related criticisms as biased, potentially weakening the link between citizens' deficit prioritization and the national policy agenda. Thus, in addition to the attendant politico-economic challenges of reducing government deficits, partisan politicization of government overspending may well serve to further perpetuate the intractability of deficit reduction.

\section{Appendix}

See Fig. 7

\footnotetext{
${ }^{21}$ For example, in a recent CBS News Poll, $80 \%$ of Republicans viewed Inflation (which rose substantially between 2021 and 2022) as a "Very Important" criterion for evaluating President Biden whereas only $59 \%$ of Democrats did so (see https://www.cbsnews.com/news/inflation-economy-immigrationbiden-opinion-poll/).
} 


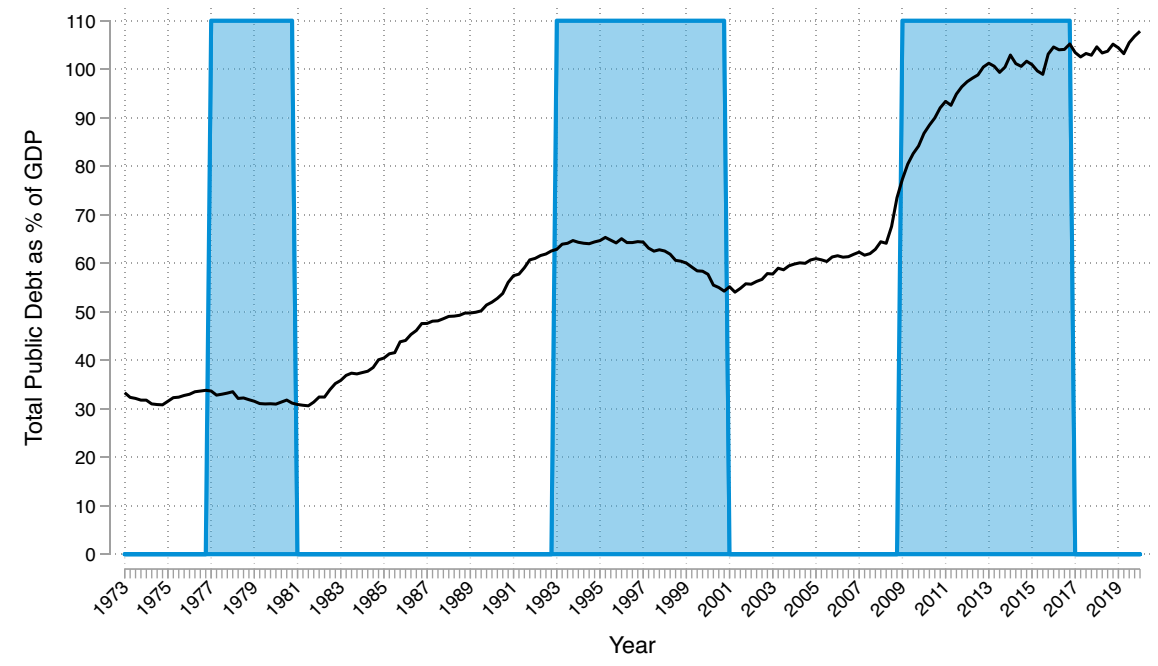

$\underline{\text { Panel B }}$

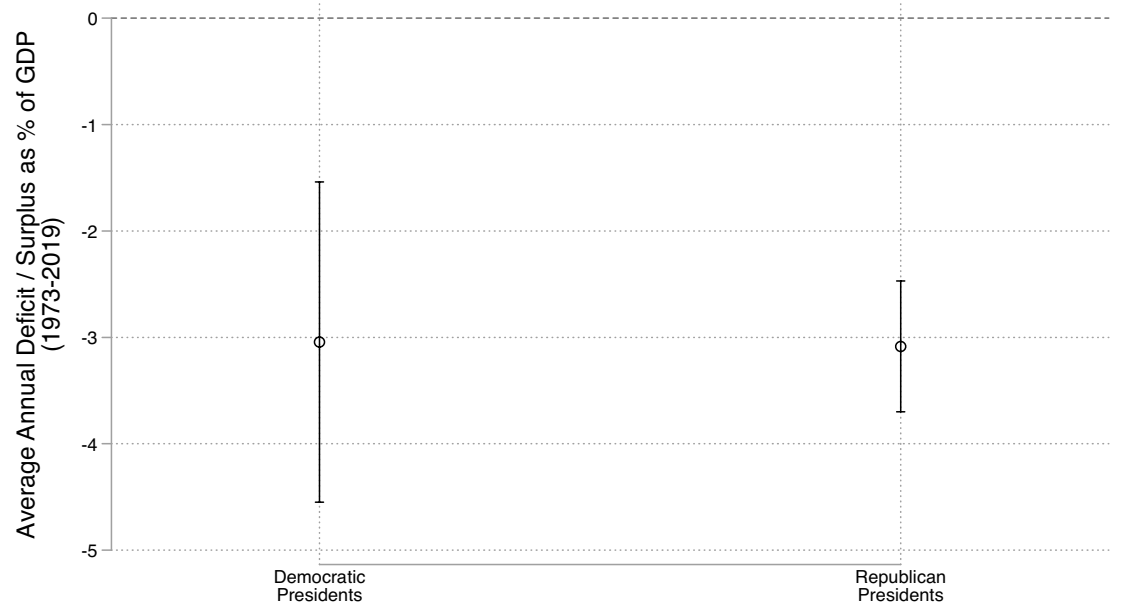

Fig. 7 Overspending across democratic and republican administrations. Notes Panel A shows quarterly total public debt as a share of GDP from 1973 through 2019; shaded regions indicate Democratic presidencies. Panel B shows average annual deficit/surplus as a share of GDP from 1973 through 2019, with negative values indicating a deficit (Democratic (Republican) mean $=-3.09(-3.04)(p=.98$ with SEs clustered by presidency). Data obtained from St. Louis Federal Reserve Economic Data (FRED))

Supplementary Information The online version contains supplementary material available at https://doi. org/10.1007/s11109-022-09783-5.

Acknowledgements The authors wish to thank Kazuki Nakamura for outstanding assistance with the content analysis portion of this study, Andy Luttrell for his thoughtful guidance on social-psychological literatures related to our theory, and Roy Meyers for helpful feedback on an early draft. Finally, the authors thank the two anonymous reviewers for their encouraging feedback and thoughtful comments. 


\section{References}

Achen, C. H., \& Bartels, L. M. (2016). Democracy for realists: Why elections do not produce responsive government. Princeton University Press.

Ansolabehere, S., \& Snyder, J. M. (2000). Valence politics and equilibrium in spatial election models. Public Choice, 103(3), 327-336.

Barber, M., \& Pope, J. C. (2019). Does party trump ideology? Disentangling party and ideology in America. American Political Science Review, 113(1), 38-54.

Bisgaard, M. (2015). Bias will find a way: Economic perceptions, attributions of blame, and partisanmotivated reasoning during crisis. The Journal of Politics, 77(3), 849-860.

Bisgaard, M. (2019). How getting the facts right can fuel Partisan-motivated reasoning. American Journal of Political Science, 63(4), 824-839.

Bisgaard, M., \& Slothuus, R. (2018). Partisan elites as culprits? How party cues shape Partisan perceptual gaps. American Journal of Political Science, 62(2), 456-469.

Bolsen, T., Druckman, J. N., \& Cook, F. L. (2014). The Influence of Partisan Motivated Reasoning on Public Opinion. Political Behavior, 36(2), 235-262.

Bolsen, T., \& Leeper, T. J. (2013). Self-interest and attention to news among issue publics. Political Communication, 30(3), 329-348.

Boninger, D. S., Krosnick, J. A., \& Berent, M. K. (1995). Origins of attitude importance: self-interest, social identification, and value relevance. Journal of Personality and Social Psychology, 68(1), 61-80.

Boydstun, A. E. (2013). Making the news: Politics, the media, and agenda setting. University of Chicago Press.

Bullock, J. G., Gerber, A. S., Hill, S. J., \& Huber, G. A. (2015). Partisan bias in factual beliefs about politics. Quarterly Journal of Political Science, 10(4), 519-578.

Bullock, J. G., \& Lenz, G. (2019). Partisan bias in surveys. Annual Review of Political Science, 22(1), 325-342.

Canes-Wrone, B., \& Shotts, K. W. (2004). The conditional nature of presidential responsiveness to public opinion. American Journal of Political Science, 48(4), 690-706.

Coe, K., Tewksbury, D., Bond, B. J., Drogos, K. L., Porter, R. W., Yahn, A., \& Zhang, Y. (2008). Hostile news: Partisan use and perceptions of cable news programming. Journal of Communication, 58(2), 201-219.

Cohen, G. L. (2003). Party over policy: The dominating impact of group influence on political beliefs. Journal of Personality and Social Psychology, 85(5), 808-822.

Coppock, A., \& McClellan, O. A. (2019). Validating the demographic, political, psychological, and experimental results obtained from a new source of online survey respondents. Research \& Politics, $6(1), 1-14$.

Crosby, A., \& Holbrook, A. L. (2019). Public support for a balanced budget amendment to the U.S. constitution: Trends and predictors. Public Budgeting \& Finance, 39(2), 44-67.

Dafoe, A., Zhang, B., \& Caughey, D. (2018). Information equivalence in survey experiments. Political Analysis, 26(4), 399-416.

Geus, De., \& Roosmarijn, A. (2019). When partisan identification and economic evaluations conflict: A Closer Look at Conflicted Partisans in the United States. Social Science Quarterly, 100(5), $1638-1650$.

Dennis, S. T. (2019). The debt ceiling-Bloomberg. Bloomberg. Retrieved July 11, 2019, from https:// www.bloomberg.com/quicktake/the-debt-ceiling.

Desilver, D. (2018). Constitutional amendments in U.S. rarely go anywhere." Pew Research Center (blog). Retrieved April 12, 2018, from https://www.pewresearch.org/fact-tank/2018/04/12/a-look-atproposed-constitutional-amendments-and-how-seldom-they-go-anywhere/.

Dickerson, B. T., \& Ondercin, H. L. (2017). Conditional motivated reasoning: How the local economy moderates partisan motivations in economic perceptions. Political Research Quarterly, 70(1), 194-208.

Egan, P. J. (2013). Partisan priorities: How issue ownership drives and distorts American politics. Cambridge University Press.

Evans, G., \& Pickup, M. (2010). Reversing the causal arrow: The political conditioning of economic perceptions in the 2000-2004 U.S. Presidential election cycle. The Journal of Politics, 72(04), 1236-1251. 
Feldman, S. (1988). Structure and consistency in public opinion: The role of core beliefs and values. American Journal of Political Science, 32(2), 416.

Feldman, S., \& Zaller, J. (1992). The political culture of ambivalence: Ideological responses to the welfare state. American Journal of Political Science, 36(1), 268.

Festinger, L. (1962). A theory of cognitive dissonance. Stanford University Press.

Fisher, L. (2012). Presidential budgetary duties. Presidential Studies Quarterly, 42(4), 754-790.

Flynn, D. J., Nyhan, B., \& Reifler, J. (2017). The nature and origins of misperceptions: Understanding false and unsupported beliefs about politics. Political Psychology, 38(February), 127-150.

Fournier, P., Blais, A., Nadeau, R., Gidengil, E., \& Nevitte, N. (2003). Issue importance and performance voting. Political Behavior, 25(1), 51-67.

Gaines, B. J., Kuklinski, J. H., Quirk, P. J., Peyton, B., \& Verkuilen, J. (2007). Same facts, different interpretations: Partisan motivation and opinion on Iraq. Journal of Politics, 69(4), 957-974.

Gerber, A. S., \& Green, D. P. (2012). Field experiments: Design, analysis, and interpretation. W. W. Norton \& Company.

Gerber, A. S., \& Huber, G. A. (2009). Partisanship and economic behavior: Do partisan differences in economic forecasts predict real economic behavior? American Political Science Review, 103(03), $407-426$.

Grossmann, M., \& Hopkins, D. A. (2016). Asymmetric politics: Ideological republicans and group interest democrats. Oxford University Press.

Gruszczynski, M. (2019). Evidence of partisan agenda fragmentation in the American public, 19592015. Public Opinion Quarterly, 83(4), 749-781.

Heilbroner, R. L., \& Bernstein, P. L. (1989). The debt and the deficit: False alarms/real possibilities. Norton.

Hill, S. J. (2021). A theory of intensity, electoral competition, and costly political action. The Journal of Politics. https://doi.org/10.1086/714922

Jacobson, L. (2015). PolitiFact I Pie chart of 'federal spending' circulating on the internet is misleading. Politifact. Retrieved August 17, 2015, from https://www.politifact.com/factchecks/2015/aug/17/ facebook-posts/pie-chart-federal-spending-circulating-internet-mi/.

Jerit, J., \& Barabas, J. (2012). Partisan perceptual bias and the information environment. The Journal of Politics, 74(03), 672-684.

Jones, B. D., \& Baumgartner, F. R. (2004). Representation and agenda setting. Policy Studies Journal, 32(1), 1-24.

Jones, P. E. (2019). Partisanship, political awareness, and retrospective evaluations, 1956-2016. Political Behavior, 42, 1-23.

Kane, J. V. (2016). Control, accountability, and constraints: Rethinking perceptions of presidential responsibility for the economy. Presidential Studies Quarterly, 46(2), 335-364.

Kane, J. V., \& Barabas, J. (2019). No harm in checking: Using factual manipulation checks to assess attentiveness in experiments. American Journal of Political Science, 63(1), 234-249.

Kennedy, B. (2020). U.S. concern about climate change is rising, but mainly among democrats. Pew Research Center (blog), April 16, 2020. https://www.pewresearch.org/fact-tank/2020/04/16/u-sconcern-about-climate-change-is-rising-but-mainly-among-democrats/.

Kessler, G. 2016. Trump's nonsensical claim he can eliminate $\$ 19$ trillion in debt in eight years. Washington Post, April 2, 2016. https://www.washingtonpost.com/news/fact-checker/wp/2016/04/02/ trumps-nonsensical-claim-he-can-eliminate-19-trillion-in-debt-in-eight-years/.

Kinder, D. R., \& Kalmoe, N. P. (2017). Neither liberal nor conservative: Ideological innocence in the American public. University of Chicago Press.

Krosnick, J. A. (1990). Government policy and citizen passion: A study of issue publics in contemporary America. Political Behavior, 12(1), 59-92.

Krugman, P. R. (2000). The return of depression economics. New York: W. W. Norton \& Company.

Lavine, H. G., Johnston, C. D., \& Steenbergen, M. R. (2012). The Ambivalent partisan: How critical loyalty promotes democracy. Oxford University Press.

Lecheler, S., de Vreese, C., \& Slothuus, R. (2009). Issue importance as a moderator of framing effects. Communication Research, 36(3), 400-425.

Leeper, T. J., \& Slothuus, R. (2014). Political parties, motivated reasoning, and public opinion formation. Political Psychology, 35(S1), 129-156.

Levitan, D. (2019). The green new deal costs less than doing nothing. The New Republic, May 3, 2019. https://newrepublic.com/article/153702/green-new-deal-costs-less-nothing. 
Lewis-Beck, M. S., Jacoby, W. G., Norpoth, H., \& Weisberg, H. F. (2008). The American voter revisited. University of Michigan Press.

Liu, J. L., \& Eibner, C. (2019). "National health spending estimates under medicare for all:" Product page. RAND Corporation. https://www.rand.org/pubs/research_reports/RR3106.html.

Lodge, M., \& Taber, C. S. (2013). The rationalizing voter. Cambridge University Press.

Mann, T. E., \& Ornstein, N. J. (2013). It's even worse than it looks: How the American constitutional system collided with the new politics of extremism. Basic Books.

Mason, L. (2015). 'I disrespectfully agree': The differential effects of partisan sorting on social and issue polarization. American Journal of Political Science, 59(1), 128-145.

Mason, L. (2018). Uncivil Agreement: How Politics Became Our Identity. University of Chicago Press.

Meirick, P. C. (2016). Motivated reasoning, accuracy, and updating in perceptions of bush's legacy. Social Science Quarterly, 97(3), 699-713.

Morgan, I. (2009). The age of deficits: Presidents and unbalanced budgets from Jimmy Carter to George W. Bush. Lawrence: University Press of Kansas.

Mullinix, K. J. (2016). Partisanship and preference formation: Competing motivations, elite polarization, and issue importance. Political Behavior, 38(2), 383-411.

Newman, B. (2013). Polls and elections: Decreasing the economy's impact on evaluations of the president: An experiment on attribution framing. Presidential Studies Quarterly, 43(4), 866-882.

Pew Research Center. (2019). Public's 2019 priorities: Economy, health care, education and security all near top of list. Pew Research Center, U.S. Politics \& Policy. https://www.pewresearch. org/politics/2019/01/24/publics-2019-priorities-economy-health-care-education-and-secur ity-all-near-top-of-list/.

Rudolph, T. J. (2003). Who's responsible for the economy? The formation and consequences of responsibility attributions. American Journal of Political Science, 47(4), 698-713.

Rudolph, T. J. (2006). Triangulating political responsibility: The motivated formation of responsibility judgments. Political Psychology, 27(1), 99-122.

Simon, L., Greenberg, J., \& Brehm, J. (1995). Trivialization: The forgotten mode of dissonance reduction. Journal of Personality and Social Psychology, 68(2), 247-260.

Sirin, C. V., \& Villalobos, J. D. (2011). Where does the buck stop? Applying attribution theory to examine public appraisals of the president. Presidential Studies Quarterly, 41(2), 334-357.

Slothuus, R., \& de Vreese, C. H. (2010). Political parties, motivated reasoning, and issue framing effects. The Journal of Politics, 72(3), 630-645.

Steinhauser, P. (2009). Poll: Unemployment is Americans' top economic concern-CNN.Com. CNN Politics, March 16, 2009. https://www.cnn.com/2009/POLITICS/03/16/unemployment.poll/index.html.

Stokes, D. E. (1963). Spatial models of party competition. American Political Science Review, 57(2), 368-377.

The New York Times. (2008). Obama delivers speech on economy. June 9, 2008. https://www.nytimes. com/2008/06/09/us/politics/09transcript-obama.html.

Thomas, K. A., \& Clifford, S. (2017). Validity and mechanical Turk: An assessment of exclusion methods and interactive experiments. Computers in Human Behavior, 77(December), 184-197.

Wood, B. D. (2004). Presidential rhetoric and economic leadership. Presidential Studies Quarterly, 34(3), 573-606.

Zell, E., C. A. Stockus, and M. J. Bernstein. (2021). It's their fault: Partisan attribution bias and its association with voting intentions. Group Processes \& Intergroup Relations, April, 1-18.

Publisher's Note Springer Nature remains neutral with regard to jurisdictional claims in published maps and institutional affiliations. 